\title{
Anthropized Agrarian Landscape in the Central-west of Tunisia: Attempts to Evaluate the Production's Systems of Apples-trees Orchards in the Delegation of Sbiba
}

\section{Hayet Ilahi $^{1}$, Islem Saadaoui ${ }^{2}$, Christopher R. Bryant ${ }^{3}$, Hichem Rejeb ${ }^{4}$}

${ }^{1 \& 2}$ Doctoral Candidate, ISA-IRESA, University of Sousse, TUNISIA

${ }^{3}$ Professor, Department of Geography, University of Montreal, CANADA

${ }^{4}$ Professor, ISA-IRESA, University of Sousse, TUNISIA

\begin{abstract}
The delegation of Sbiba is characterized by a specific agricultural stamp; it is the "true oasis" of the Central-west of Tunisia. This study consists in characterizing the agrarian landscape as "a product" of the agricultural systems. On the basis of the apple orchards example, we try to create a reflection on the articulations between material and ideational dimensions of the landscape production through transdisciplinary analysis; spatial and agricultural analysis. The results showed that the systems of production of apple orchards at Sbiba are characterized especially by the micro properties, $65 \%$ of orchards superficies are lower than 5 ha, even so, apple's productions remain fairly important (10 $\mathrm{t} / \mathrm{ha}$ ). The perception of the agrarian landscape with the use of the Quotation method shows that this zone is a rural region characterized by its agricultural aspect and an abundance of apple orchards.
\end{abstract}

Keywords: Landscape, apple orchards, agrarian system, production of landscape, perception of space

\section{INTRODUCTION}

The agriculture, very often, appears as an activity that contributes to the production of landscapes insofar as, it arranges space, the structure and transforms it. The agricultural landscapes, in their material dimensions, can thus be approached as the result of the operation of the agricultural systems in space (Benoit, 1990; Poinsot, 2008).

The equilibrium that governs the production of landscape by agriculture is nevertheless dependent on many factors whose hierarchy may considerably vary according to the local contexts (pedologic and climatic parameters, the orientations of the production systems, level of technical knowledge, land structures, level of economic integration, public policies, organization of the social reports). In spite of this variability and to exceed a vision (too much) deterministic, the comprehension of this landscape production by agriculture cannot be freed from a detailed analysis of farmer's practices. 
Indeed, while being interested at the most elementary level of landscape production, here the agricultural practices, that we can try to release from common logic to various regional contexts (Deffontaines, 1996).From a year to another, the apple sector in the central-west of Tunisia becomes increasingly important; gradual the ways of cultivation, then, the landscapes become increasingly improved. The apple of Sbiba has become a significant product that characterizes the entire region.

Accordingly, the first phase often consists to analyze the forms of the apple orchard landscape, their localization and their fitting. Once this phase of spatial analysis carried out, it then occurs to understand which are the functions that take part in the production of these forms and thus to define the landscape-object. Only, if the material dimension of the landscape remains relatively simple to insulate for the researcher (landscape-object), logic of the production of this "landscape-object" are much less (Deffontaines, 2004), This approach then places the farmers and their actions in the center of a multi-scalar system in which articulate at the same time material dimensions and perceptions of the landscape, but also individual and collective dimensions of their practices (From the Landes and al., 1988).

The first part of this article clarifies the pre-necessary which must be considered for the spatial analysis and the characterization of the landscape of apple orchard (functional dimension). In the second part, we seek to reveal the articulation between the individual dimension of the practices and perceptions (space and landscape).

\section{Methodologies}

\section{Site of Study}

Sbiba's delegation located in Kasserine Governorate, in the central-west of Tunisia (Figure 1), covers a superficies of 46253 ha (5.6\% of the total surface area of the Governorship).

The semi-arid climate is strongly marked by the continentality; the seasonal rainfall mode is of the type APHE in which the summer remains the first dry season and the winter the second (Chabbani, 1992), the annual average temperature with Sbiba is of $19.3^{\circ} \mathrm{C}$. The useful agricultural superficies are evaluated to approximately 44969 ha (97\% of the total surface area of the delegation), where the arboriculture is the dominant culture. An old tradition of irrigation by rudimentary means (sources, wells and derivation of wadi water) remained and supported until our days, by 1920, the beginning of the work of installation of an irrigated perimeter using water of Sbiba's wadi (Bonvallot and Hamza, 1980), has encouraged the development of an intensive farming.

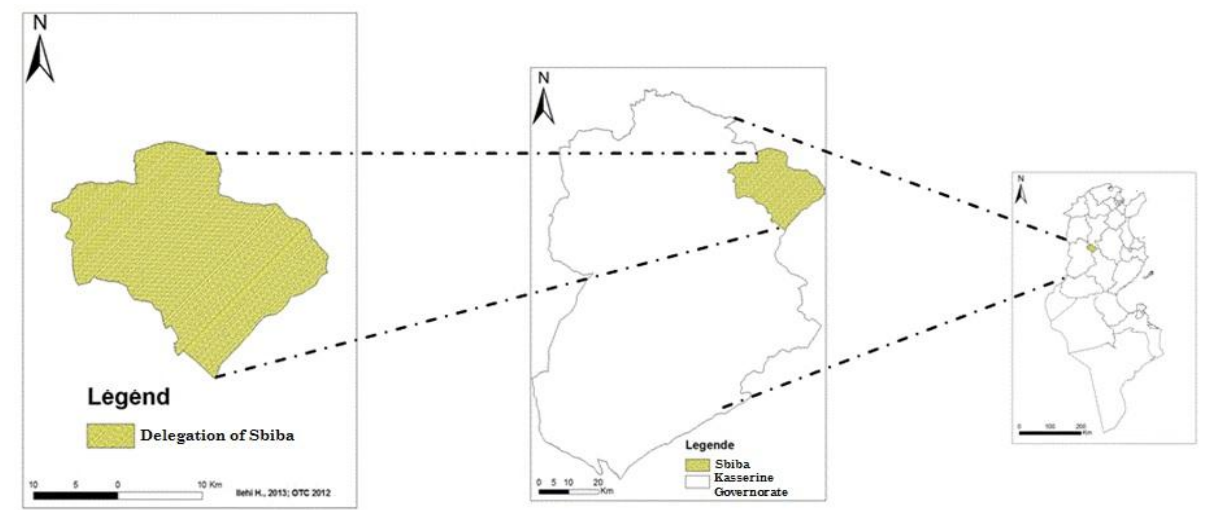

Figure 1: Geographical location of the delegation Sbiba 


\section{Methods}

\section{Spatial analysis like precondition under investigation of the agricultural systems}

This analysis relies on an exhaustive investigation near the arborists of the area of Sbiba. To determine the main features of the production systems of apple orchard in this area we focused to identify those various following factors:

- The spatial distribution of an apple orchard: Old, surface, layer, varieties cultivated,

- Characterization of farming activities,

- Yields of apple orchard.

\section{Application of Neuray's Quotation Method: Test of valorization of the apple orchard}

This analysis presupposes the taking into account the most borrowed points of perception, attended (path of seats from exploitation, point of view, existing elements in the observed area).

With the aim of the determination of the landscape value using the method of QUOTATION OF NEURAY, we visited the site of study in order to select a point of observation.

The quotation method provides only landscape values; it rests on an analysis of the sights taken at the significant places. It gives at the same time a global value of the landscape and a separate evaluation of the various significant components. The method takes account of the principle of RECIPROCITY (if I see I am seen) [Toussaint, 2009].

From the point of observation, we determine several data:

- The length, orientation and the broadness of outlook,

- Vertical dimensions of the site,

- Factors of valorization,

- The basic value of the site.

The basic value of the site is calculated according to the following formula: V = LXRXS. This value basic of the sight represents a current situation of the landscape perceived starting from a point of view. The quotation of the sum of the value of the elements added to the basic value gives the total value of the site according to the formula: $V^{\prime}=V+\sum e=L X R X S+\sum e$. The sum of the values of the elements takes account of their nature.

- $\quad$ Site of observation

Geographical coordinates of the apple orchard:

Latitude:35'31'458'NR

Longitude:94'429"E
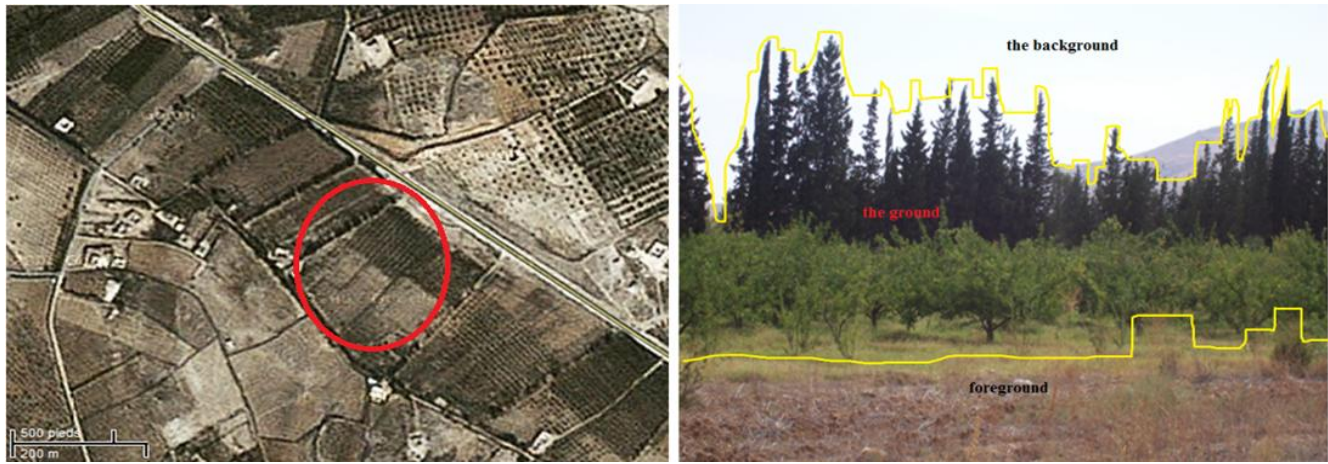

Figure 2: Sight of the apple orchard: object of the landscape reading 


\section{RESULTS}

\section{Production system in apple orchard at Sbiba}

Age of apple orchard

The database of the investigation carried out shows us that:

- $40 \%$ of farms are cultivated by crops in heterogeneous ages,

- $16.2 \%$ of exploitations, whose age is distributed between 5 and 10 years,

- $16.2 \%$ between 10 to 20 years,

- $16.4 \%$ with old plantations (more than 21 years),

- The young plantations do not exceed $11.2 \%$.

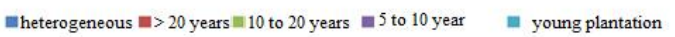

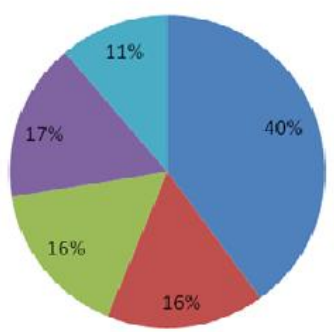

Figure 3: Ages of apple orchard

The distribution of the sum of areas, regardless of heterogeneous orchards depending on the classes of age of apple trees, shows that most of the plantations are aged between 11 and 20 years.

\section{Crumbling of the micro-exploitation and consolidation of the average farms}

\section{Superficies distribution}

The distribution of orchards is defined by layers for which one a:

- The first strata going from 0 to 2 ha: represents $34.61 \%$ of apple orchard,

- The second strata from 2 to 5 ha: $30.76 \%$ of apple orchard,

- The third strata from 5 to 10 ha: $23.07 \%$ of orchards,

- The fourth strata superiors to 10 ha: $7.69 \%$ of orchards.

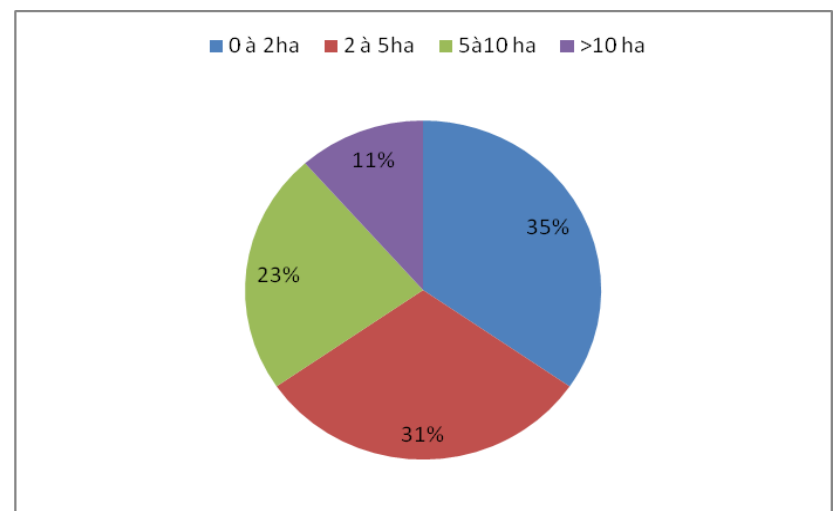

Figure 4: Distribution of apple orchard according to strata 
The figure shows a dominance of farms in which the superficies are less than $10 \mathrm{~h}$. The average area per holding is 5.11 ha.

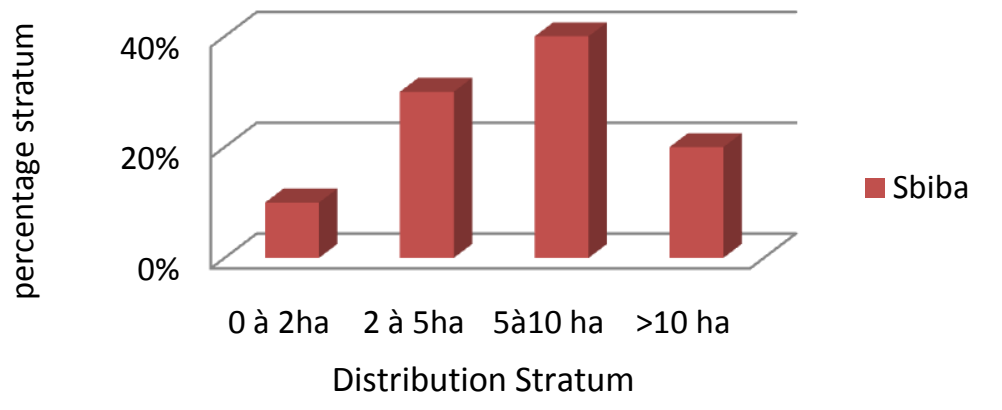

Figure 5: Distribution of orchard's superficies

\section{Structure orchards}

The apple trees crops are led in monoculture by more than $50 \%$ of the surveyed farmers. Our results show us that an apple orchard can be homogeneous where we find only the two varieties Golden and Richared Delicious with a percentage of $60 \%$. In addition, these orchards can be heterogeneous.

Indeed, the varieties presented previously are cultivated with local varieties (Zina, Aziza, etc.) with a percentage of $11 \%$, and/or other varieties introduced like Starkrimson, Red chief, Golden delicious spur, with a percentage of $29 \%$.

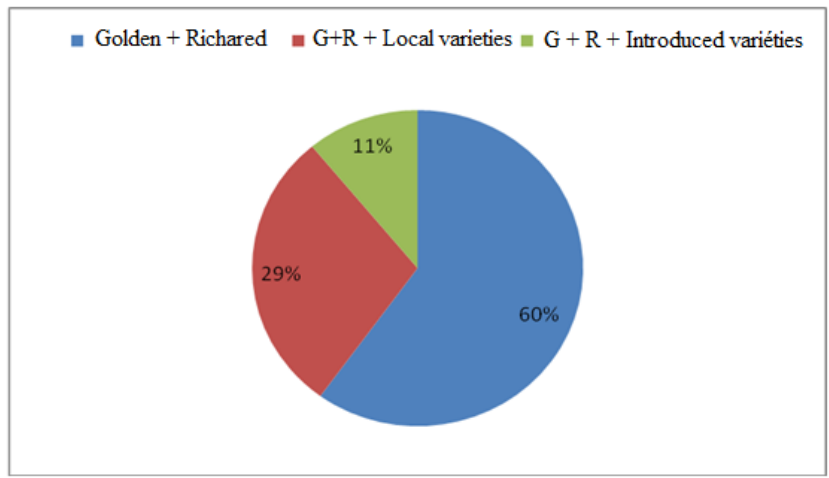

Figure 6: Cultivated varieties

The varieties Golden delicious and Richared are cultivated by all the farmers of the region. Water is the limiting factor of the production for the apple tree. For that, we were interested to identify the different ways to exploit water of irrigation.

It arises that we have five groups:

- group I: it represent the majority $(48 \%)$, farmers are making recourse to water resources exploited by public wells of surface,

- group II: they exploit water of private well, having a percentage of $10 \%$,

- group III: they exploit water of the public irrigated perimeter (PPI) with a percentage of $23 \%$,

- group IV: they exploit water of private driling, with a percentage of $11 \%$, group V: $8 \%$ of the owners use water of irrigated perimeter using private wells of surface. 


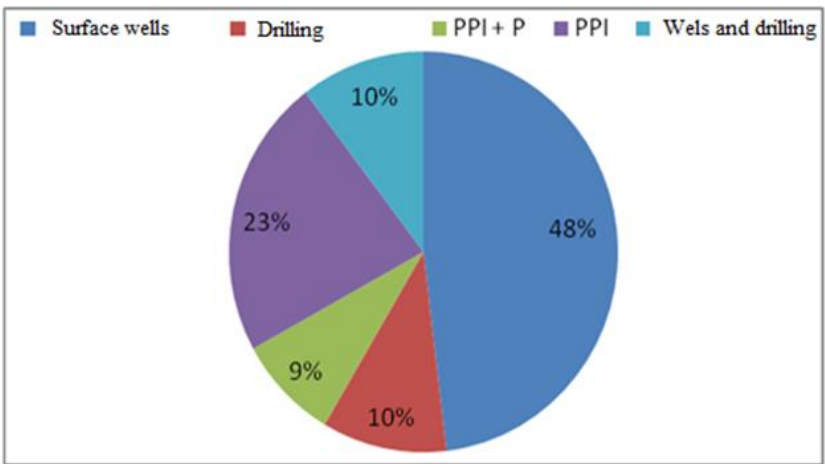

Figure 7: Sources of irrigation water

The management of the water resources is deduced starting from modes and irrigation's frequencies.

- The mode of irrigation per "irrigation channel: Seguia" is the most used, it represents $42.3 \%$.

- The mode of localized irrigation mode represents 30.76\%.

- The rest of the farmers simultaneously have these two modes of irrigation (27.92\%).

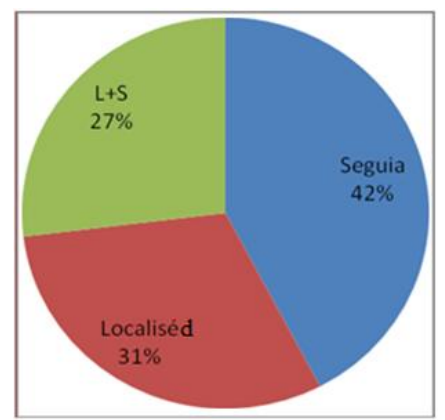

Figure 8: Modes of irrigation

The pruning of the fruit trees

The database of the investigation concerning the pruning classifies the farmers into two groups:

- $\quad$ 1st group: $82 \%$ of farmers are practicing an annual pruning,

- $\quad$ 2nd group: $18 \%$ of farmers are practicing the bi-annual pruning.

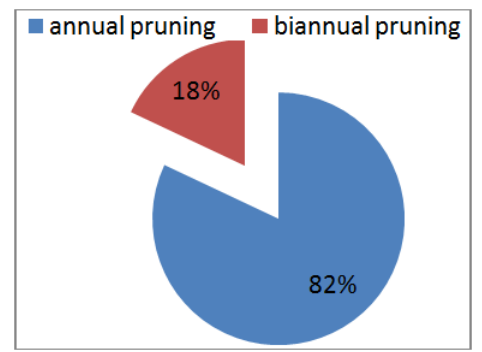

Figure 9: Mode of pruning

\section{Evaluation of the expertise of farmers}

The conducted survey enables us to evaluate the knowledge levels of the farmers concerning some cultivation practices. This figure shows the weaknesses especially about the application of phytosanitary treatments and practice of fruit thinning. 


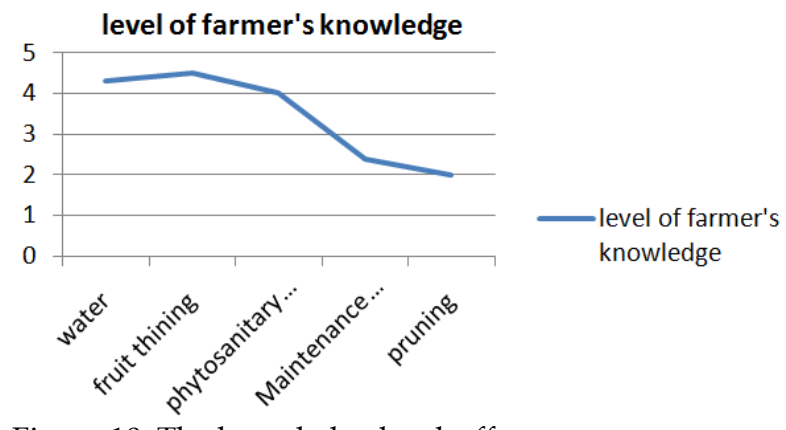

Figure 10: The knowledge levelsoffarmers

\section{Evaluation of the productivity of apple-trees orchard}

The average yields across the Governorate is $10 \mathrm{t} / \mathrm{ha}$.

The results of the study show that:

$-57.69 \%$ of the surveyed farmers gather an average yield ranging from 5 to $10 \mathrm{t} / \mathrm{ha}$,

- $15.38 \%$ of the surveyed farmers gather an average yield ranging from 10 to $20 \mathrm{t} / \mathrm{ha}$,

- $26.98 \%$ of the surveyed farmers gather an average yield of more than $20 \mathrm{t} / \mathrm{h}$.

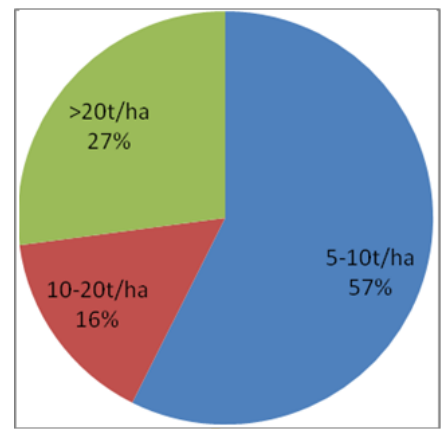

Figure 11: Average yields for agricultural season 2010/2011.

According to the statistics of yields, we see fairly large variations from one year to another, which is quite remarkable in Figure 12.

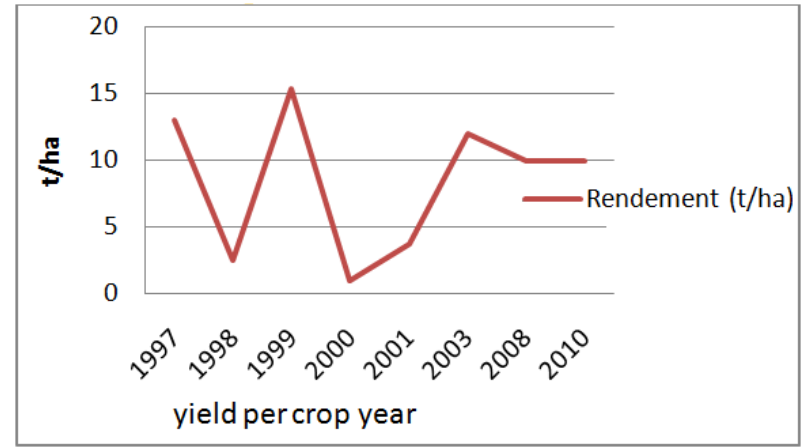

Figure 12 
Agricultural landscape Analysis: Reading the apple orchard landscape using Neuray's Quotation method

Table I. Landscape Valorofan apple orchard at Sbiba

\begin{tabular}{|c|c|}
\hline & Observation point \\
\hline Orientation & $40^{\circ}$ Nord \\
\hline Altitude $(\mathrm{m})$ & $944 \mathrm{~m}$ \\
\hline $1(\mathrm{~m})$ & 9 \\
\hline $\begin{array}{l}\text { Length of sight } \\
\mathbf{L}=1 / 2.10 . \log 101 \\
1=\text { major length of the view } \\
\text { expressed in } \mathrm{cm} .\end{array}$ & $\begin{array}{l}14,77 \mathrm{~cm} \\
0.1477 \mathrm{~m}\end{array}$ \\
\hline $\begin{array}{c}\text { Angle } \alpha \\
\alpha: \text { theangleformedbythehorizontaloneandforegroundon30mapproxi } \\
\text { mately }\end{array}$ & $46^{\circ}$ \\
\hline $\begin{array}{c}\text { Angle } \beta \\
\beta: \text { l'angle formée par l'horizontal et une ligne tangente à la partie la } \\
\text { plus élevé de l'avant plan }\end{array}$ & $4^{\circ}$ \\
\hline $\begin{array}{c}\text { Angle } \gamma \\
\gamma: \text { the angle formed by the horizontal and a line tangent to the top } \\
\text { of the elements are located more than } 50 \mathrm{~m} .\end{array}$ & 9 \\
\hline $\begin{array}{c}\text { vertical dimensions } \\
\mathbf{R}=\mathbf{1}+\sin \boldsymbol{\alpha}+\sin \boldsymbol{\beta}+\sin \gamma+\mathrm{d} / \mathbf{1 0 0} \\
\mathrm{d}: \text { the Difference level actually received in meters }\end{array}$ & 1.965 \\
\hline First value of the Landscape: $\mathbf{V}^{\prime}=\mathbf{L} \cdot \mathbf{R}$ & 0.2903 \\
\hline \multicolumn{2}{|l|}{ Factors Valuation: } \\
\hline Water & 0 \\
\hline Rocks, acute mountain & 5 \\
\hline open spaces & 2 \\
\hline successive plans & 5 \\
\hline Framing and polarization & 1 \\
\hline La ligne de crête & 5 \\
\hline Répartition des éléments dans la zone du paysage à $(1000 \mathrm{~m})$ & 2 \\
\hline Répartition des éléments dans l'arrière-plan (+1000m) & 1 \\
\hline Relief & 4 \\
\hline Voies de communication & -1 \\
\hline Intégrité (homogénéité et harmonie) & 2 \\
\hline $\mathrm{T}$ & 26 \\
\hline$S=1+T / 10$ & 3.6 \\
\hline $\begin{array}{c}\text { Valeur de base de la vue } \\
\mathbf{V}^{\prime \prime}=\text { L.R.S } \\
\mathrm{L}=\text { la longueur de la vue } \\
\mathrm{R}=\text { les dimensions verticales de la vue } \\
\mathrm{S}=\text { les facteurs de valorisation }\end{array}$ & 1.045 \\
\hline Pommiers & 4 \\
\hline Cyprès & 6 \\
\hline Montagnes & 0 \\
\hline Constructions & 6 \\
\hline Somme des $\mathbf{i}: \quad \sum \mathbf{i}$ & 16 \\
\hline
\end{tabular}




\section{Valeur de la vue \\ $\mathbf{V}=\mathbf{L} . \mathbf{R} . \mathbf{S}+\sum \mathbf{i}$ \\ $\mathrm{L}$ : la longueur}

$\mathrm{R}$ : les dimensions verticales de la vue

$S$ : les facteurs de valorisation

La somme de la valeur des éléments
17.045

From the results obtained after evaluating the region's landscape, the landscape values are equal to 17.41.

The perception of the agricultural landscapes shows that the area is a zone with rugged reliefs; we notice a clear distribution of the apple trees and Cypress plantation. We have to note that the study site is a zone with rural stamp.

Finally the value allotted to the sight observed informs us about the landscape, wealth in the zone of study. Nevertheless, the apple orchard landscape is a very common landscape in central-west of Tunisia. It is about a landscape with sloping relief and an important agricultural occupation (generally of larger batches of the fruit trees).

\section{Discussion}

The spatial analysis results show that:

- Many orchards are aged (sometimes of more than 50 years).

- The principal cultivated varieties are Golden and Richared Delicious. The exploitations having heterogeneous plantation's age are about $40 \%$.

- The parceling out and the low size of the farms constitute an obstacle to develop the production.

The irrigation water is, in most orchards visited, available in sufficient quantity and quality is generally quite satisfactory, which leads to an overdose of water supplies. The resulting waste is often accompanied by unnecessary fertilizer inputs, probably harmful one hand, and a leaching of nutrients other. Also, the absence or insufficiency of water modulation intake and thus fertilizer, according to the vegetative stages of crops, could be at the origin of the problems noted of excessive fall of the young fruits after a well successful nouaison.

However, certain cases of deficit out of irrigation's water were encountered, either for lack of water, or by voluntary saving in water, or in consequence of the adoption of equipment of localized irrigation inappropriate or an ignorance of its effective use. This hydrous deficit is reflected on several components of the output, of which most significant is the caliber of the fruits.

Although, systems of production in the region do not have enough modern technology to improve the production of orchards, we find that the performance is moderately high, but the average yield per year is not stable from year to year another, this variation can be explained by the fact that the apple trees are characterized by a phenomenon of alternation, but we must not neglect the unstable harsh climatic conditions (hail, temperature, and sometimes not sufficient humidity ...).

The study of apple orchard landscape with the help of the method of quotation of Neuray with Sbiba indicates to us the highest landscape value of the studied site, the computed value supports the choice to preserve and improve agrarian space of the area. It can be taken into accounts by the concerned actors to install agricultural projects in this zone. 


\section{CONCLUSION}

Through the elements developed in this study, various dimensions of the practices appear essential for understanding how to produce the landscape. The taking into account of the useful dimension of farming practices makes it possible to highlight the individual production of landscape by the farmers. Moreover, links between the processes of construction of the representations and social norms (reference frames of behavior, representations of the landscape...) within the agricultural sociability networks and the manners that have the farmers to conceive their practices (utility, pleasure), allows for better understanding how the individual and collective scales of the production of landscape are articulated.

\section{REFERENCES}

Benoit Mr. (1990). "Territorial management of the farming in a Lorraine village", Map of the world, vol.4, p.15-17.

Deffontaines J.P. (1996). "Landscape like means of knowledge of the farming to the farming like means of production of landscape. The producing farmer of landscapes. A point of view of agronomist", Reports of the Academy of agriculture of France, vol. 82, vol.4,p. 57-69.

Deffontaines J.P. (2004). "The object in agricultural space. The glance of a géo-agronomist", Natural Sciences Companies, vol. 12, p. 299-304.

From the Landes E., Deffontaines J.P. and Benoit M. (1988). "Practices of the farmers. Point of view on a new current of the agronomic research", Rural Studies, vol. 109, p. 125-158.

Poinsot Y. (2008). How agriculture manufactures its landscapes. A geographical glance on the evolution of the campaigns of Europe, ofthe Andes, and Black Africa, Paris, Karthala, collar. Men and Companies, $243 \mathrm{p}$. 